\title{
Effect of Foot Reflexology on Fatigue, Stress and Serum Cortisol Levels in Women with Multiple Sclerosis
}

\author{
Nusrat Ebrahimi ${ }^{1}$, Marzieh Loripour² ${ }^{2}$ Alireza Sayadi ${ }^{3}$, Ali Mellat Ardakani ${ }^{4}$, Ahmad Reza Sayadi ${ }^{5}$ \\ ${ }^{1}$ Department of Internal Nursing and Surgery, Rafsanjan University of Medical Sciences, School of \\ Nursing and Midwifery, Rafsanjan, Iran. ${ }^{2}$ Department of Reproductive and Midwifery Health, Faculty \\ of Nursing and Midwifery, Elderly Research Center, Rafsanjan University of Medical Sciences, School \\ of Nursing and Midwifery, Rafsanjan, Iran. ${ }^{3}$ Department of Psychology, Shahid Sadoughi University of \\ Medical Sciences, Yazd, Iran. ${ }^{4}$ Department of Internal Medicine, Faculty of Medicine, Infectious \\ Diseases Research Center, Shahid Sadoughi University of Medical Sciences, Yazd, Iran. ${ }^{5}$ Department of \\ Psychological Nursing, School of Nursing and Midwifery, Research Center for Social Factors Affecting \\ Health, Rafsanjan University of Medical Sciences, Rafsanjan, Iran.
}

\section{ABSTRACT}

\section{BACKGROUND}

Fatigue, stress, and increased cortisol are common problems experienced by MS patients. Given that there is little research in Iran and abroad on the effects of foot reflexology, the present study explored the impact of foot reflexology on fatigue, stress, and serum cortisol levels in women with multiple sclerosis.

\section{METHODS}

In this randomized clinical trial study, conducted among 60 women with multiple sclerosis referred to Multiple Sclerosis Society of Yazd. Sampling was initially performed by targeted sampling method based on entry and exit criteria and then 60 samples were randomly divided into two groups of intervention and control using a random number table. The foot reflexology was performed for the intervention group and simple food massage was performed for the control group for 4 weeks, 3 times a week for 15 minutes for each foot. The data were collected using Fatigue Severity Scale, Stress Symptom Index, and the Demographic Information Form, and analysed using the chi-square test, independent samples t-test, and two-way repeatedmeasures ANOVA with SPSS software (Version 18).

\section{RESULTS}

The mean serum levels of cortisol and fatigue showed a significant decrease at different times in the intervention group compared to the control group $(\mathrm{P}<0.00001)$. The mean stress scores in the intervention group were significant in the pre-testpost-test and pre-test-follow-up phases $(\mathrm{P}<0.00001)$ but not significant in the posttest phase with one-month follow-up $(\mathrm{P}=0.074)$.

\section{CONCLUSIONS}

The results of the study suggested that foot reflexology has a long-term effect on fatigue and cortisol serum levels and a short-term effect on stress in women with multiple sclerosis.

\section{KEY WORDS}

Reflexology, Stress, Fatigue, Cortisol, Multiple Sclerosis
Corresponding Author: Dr. Ahmad Reza Sayadi, Department of Psychological Nursing, School of Nursing and Midwifery, Research Center for Social Factors Affecting Health, Rafsanjan University of Medical Sciences, Rafsanjan, Iran.

E-mail: sayadiahmad@yahoo.com

DOI: $10.14260 /$ jemds/2020/543

How to Cite This Article:

Ebrahimi N, Loripour M, Sayadi A, et al. Effect of foot reflexology on fatigue, stress, and serum cortisol levels in women with multiple sclerosis. J Evolution Med Dent Sci 2020;9(35):2497-2501, $10.14260 / \mathrm{jemds} / 2020 / 543$

Submission 21-05-2020,

Peer Review 14-07-2020,

Acceptance 22-07-2020,

Published 31-08-2020.

Copyright (C) 2020 JEMDS. This is an open access article distributed under Creative Commons Attribution License [Attribution 4.0 International (CC BY 4.0)] 


\section{BACKGROUND}

Multiple sclerosis is a chronic disease that results from the demyelination of the central nervous system and is an autoimmune disease. ${ }^{1}$ that often affects young and middleaged men and women. ${ }^{2}$ Multiple sclerosis is known to be the third leading cause of neurological disability in adults. ${ }^{3}$ Two and a half million people worldwide suffer from multiple sclerosis, and after brain trauma injuries, it is the most common adult neurological disorder in Western societies, affecting about 400,000 young people in the United States, and ten thousand persons are added to the affected population annually. ${ }^{4}$ Recent studies in Iran show that the prevalence of MS varies from 5.3 to 74.28 per 100,000 people, and this figure is increasing. ${ }^{5}$

The prevalence of stress in MS patients was reported to be $46.4 \%{ }^{6}$ Stress, anxiety, and depression symptoms in MS patients are closely associated with relapse and reduced quality of life.7,8 Fatigue is a common problem in MS patients, and $80 \%$ of patients complain of fatigue. ${ }^{7}$ Fatigue has a significant impact on the daily lives of these patients and hinders their physical activities and interferes with their responsibility, role, and social functioning. ${ }^{9}$

Complementary and alternative medicine (CAM) accounts for 65 to $80 \%$ of the world's care methods. ${ }^{10}$ Reflexology is a part of traditional Chinese medicine in which pressure is applied by fingers to specific parts of the body and is based on the principle that the reflection points are connected to internal organs and glands and have been designed with the same composition as the body. Since fatigue and stress have a significant impact on the daily lives of MS patients, they hinder physical activities and affect their responsibility, role, and social functioning. ${ }^{8}$ Besides, given that there are conflicting studies on reflexology, the present study aims to explore the effect of foot reflexology on fatigue, stress, and serum cortisol levels in women with multiple sclerosis.

\section{METHODS}

This study is a randomized controlled clinical trial approved by the Ethics Committee (IR.RUMS.REC.1397.026) and the code of ethics (IRCT 201803040338936N1) of the Iranian Registry of Clinical Trials on 60 women with multiple who met the criteria to enter the study in MS Clinic of Yazd. The sample size was determined as 30 persons for each group following a study by Soheili Shahreza et al. ${ }^{9}$

$$
\mathrm{n}_{2}=\mathrm{k} \times \mathrm{n}_{1} n_{1}=\frac{\left(Z_{1-\frac{\alpha}{2}}+Z_{1-\beta}\right)^{2} \times\left(\sigma_{1}^{2}+\frac{\sigma_{2}^{2}}{k}\right)}{\Delta^{2}}
$$

Using the above equation, $\mathrm{n}=17$ for each group, and 30 persons were considered for each group by taking into account the dropout rate.

$$
\begin{aligned}
& \beta=0.10 \rightarrow Z_{1-\beta}=1.29 \\
& \alpha=0.05 \rightarrow Z_{1-\frac{\alpha}{2}}=1.96
\end{aligned}
$$

Where $\sigma_{1}=0.94$ is the standard deviation for the FSS score within one month after the intervention in the intervention group, $\sigma_{2}=0.86$ is the standard deviation for the FSS score within one month after the intervention in the control group, $\mathrm{K}=1$ is the sample size which is equal for both groups, and $\Delta=$ 1 is the minimum difference in the mean of the FSS score which is clinically significant.

The inclusion criteria were not having any physical, mental and psychological illness at the same time, a history of at least one year with multiple sclerosis, non-pregnancy and non-use of corticosteroids, being at the age of 20 to 40 years, having the disease of the recurrence-depression type, having the expanded disability score of 1 to 4.5 , and the absence of lesions on the soles of the feet. The participants excluded from the study in the following cases: Not attending three consecutive sessions, not willing to further cooperate, the occurrence of an accident to them, and medication changes.

In this randomized clinical trial study, 60 women with multiple sclerosis were referred to the Yazd Multiple Sclerosis Association. Sampling was first performed by targeted sampling method based on entry and exit criteria and then 60 samples were randomly divided into two groups of intervention and control using a random number table. The data were collected using the demographic information form (including age, education, marital status, marital status, occupation, income, type of medication, duration of the illness, body mass index (BMI), and the expanded disability score), the Fatigue Severity Scale (FSS), and the Stress Symptom Index (SSI). The Fatigue Intensity Scale is a standard tool with acceptable internal consistency to measure fatigue and was used in a study by Krupp et al.10 The scale with a correlation coefficient of $r=0.84$ was confirmed for use in Iran.11 The reliability of the Stress Symptom Index (SSI) was checked by calculating the Cronbach's alpha and the corresponding values for cognitive, emotional, behavioural, and physical symptoms were $0.88,0.88,0.78,0.90$, and 0.95 , respectively. ${ }^{12}$

The data were collected by the researcher, and the participants were examined and interviewed by a neurologist and a psychologist in three stages: pre-test, post-test, and onemonth follow-up. To collect blood samples from all participants in the two groups, $10 \mathrm{cc}$ of blood was taken from the brachial fluid and poured into dry pipes. The blood samples were centrifuged at a low temperature by a centrifuge at $3000 \mathrm{rpm}$ for 15 minutes and followed by serum separation. The blood samples were immediately placed in an ice pack container and quickly transferred to the laboratory and frozen at -20 . C.

Foot reflexology was performed for the participants in the intervention group for 4 weeks, three times a week, while the participants in the control group were treated with foot sole massage at home for the same period. A reliable and capable caregiver was trained on how to perform foot reflexology, and further and follow-up instructions were provided through telephone. To train the patient care attendant, the patient was asked to lie on her back on the bed in a supine position, and then foot reflexology was performed for 30 minutes (15 minutes for each foot). To this end, direct rotational pressure was applied to the solar plexus for 6 minutes followed by 3 minutes of rest. The procedure was repeated by applying 3-4 $\mathrm{kg}$ of pressure for 6 minutes. The members of the control group were treated with simple foot massage with the same conditions and duration considered for the intervention group 
but without applying pressure on the solar plexus. The collected data were analyzed with SPSS software (version 18) using the chi-square test, independent samples t-test, and twoway repeated-measures ANOVA.

\section{RESULTS}

The means of age, duration of the disease, and body mass index in the intervention and control groups were $32.66 \pm 5.60$ vs. $32.30 \pm 5.36,7.10 \pm 4.57$ vs. $5.97 \pm 2.43$, and $25.32 \pm 3.95$ vs. $24.40 \pm 4.19$, respectively. Besides, $76.7 \%$ and $70 \%$ of the participants in the intervention and control groups were married. Concerning the education level, $26.7 \%$ and $30 \%$ of the participants in the intervention and control groups had a college education. It was shown that $56.7 \%$ and $50 \%$ of the participants in the intervention and control groups were housewives. The results of data analysis indicated that the two groups had no significant differences in terms of the demographic characteristics $(\mathrm{P}>0.05)$ (see Tables 1 and 2). According to the Kolmogorov-Smirnov test, the data were normally distributed in terms of fatigue, cortisol, and stress scores $(\mathrm{P}>0.05)$. The results also showed that there were no statistically significant differences between the two groups in terms of their mean scores for fatigue, cortisol, and stress in the pre-intervention stage $(\mathrm{P}>0.05)$.

The Mauchly test showed that the sphericity assumption was met for time and time-group effects. Therefore, it can be suggested that the assumption of inequality was met for all variables. Mauchly test was not significant for stress $(\mathrm{P}=0.452)$ but significant for fatigue and cortisol. Besides, the Greenhouse-Geisser correction was used to examine time and time-group interactive effects. As can be seen in Table 4, the measurement time has a significant effect on the scores of the research variables. Accordingly, it can be suggested that regardless of the group membership, there are significant differences between the mean scores of the research variables in the pretest, post-test, and one-month follow-up. The effect of time-group interaction is significant; showing the difference between the mean scores of the research variables at different times according to the levels of the group variables. The effect of the group on the scores for the research variables is significant, showing that regardless of the measurement time, the mean scores of the research variables show significant differences between the groups in terms of foot reflexology and foot sole massage $(\mathrm{P}=0.001)$. The results of the Bonferroni test also showed that the mean scores of stress experienced by the participants in the intervention group were significantly different in the pre-test-post-test and pre-test-follow-up stages $(\mathrm{P}<0.00001)$. However, there was no significant difference in the stress scores between the post-test and the one-month follow-up stages $(\mathrm{P}=0.074)$. The mean scores of fatigue for the participants in the intervention group were significantly different in the pre-test-post-test and pre-testfollow-up stages $(P<0.00001)$. Similarly, the mean scores of serum cortisol in the intervention group were significantly different in the pre-test-post-test and pre-test-follow-up stages $(\mathrm{P}<0.00001)$. However, the three variables did not show any significant differences for the participants in the control group all in the pre-test, post-test, and follow-up stages (P> 0.05) (Table 5).
Table 2 shows that the two groups did not differ significantly in terms of age, duration of the illness, weight, height, body mass index, and the expanded disability. To evaluate the effect of time (changes in the mean score of stress, fatigue, and serum cortisol levels in the repeated measurement times), group effects (changes in the mean score of stress, fatigue, and serum cortisol levels over repeated measurement times) and time-group interaction (changes in the mean scores of stress, fatigue, and serum levels of cortisol over time by taking into account the group effects) the twoway repeated-measures ANOVA was used. The results of the multivariate test showed that the time-group interaction effect $(\mathrm{P}<0.0001)$ and also the time effect, were statistically significant $(\mathrm{P}<0.0001)$ (Table 3$)$.

The results of the between-subject effect showed a statistically significant difference for the group effects $(\mathrm{P}<0.00001)$. Therefore, statistical modelling was used to investigate the time-group interaction effect and also examine the changes in mean scores of stress, fatigue, and serum cortisol levels in different groups and times and the interactions between them. As shown in Table 3, the measurement time has a significant effect on the mean score of stress, fatigue, and serum cortisol levels $(\mathrm{P}<0.00001)$. It can be suggested that regardless of group membership, there is a significant difference between the mean scores of the research variables before the intervention, immediately after the intervention, and three months after the intervention $(\mathrm{P}<0.00001)$.

The time-group interaction effect was also significant $(\mathrm{P}<0.00001)$, showing that the rate of decrease in the mean scores of stress, fatigue, and serum levels of cortisol in the intervention group were significantly higher than the corresponding values for the control group. This shows the significant effect of the training intervention on reducing stress, fatigue, and serum cortisol levels in MS patients. The group effect on the scores of the research variables was also significant.

As shown in Table 4, the analysis of the changes in stress scores in the intervention group in repeated measurements showed that the stress level experienced by the participants before the intervention is significantly different from their stress level immediately after the intervention and one month after the intervention $(\mathrm{P}<0.00001)$. However, there was no statistically significant difference in the stress scores immediately after the intervention and one month after the intervention $(\mathrm{P}=0.074)$. Besides, there were no significant statistical differences in the stress level experienced by the participants in the control group in the three stages $(\mathrm{P}<0.05)$. The analysis of the changes in fatigue scores in the intervention group in repeated measurements showed that the fatigue reported by the participants before the intervention is significantly different from the level of fatigue immediately after the intervention and one month after the intervention $(\mathrm{P}<0.00001)$. There was also a significant difference in the fatigue scores immediately after the intervention and one month after the intervention $(\mathrm{P}=0.037)$. However, no statistically significant difference was observed in the fatigue scores in the three stages ( $P>0.05$ ). (Table 5)

A comparison of the changes in serum cortisol levels in the intervention group in repeated measurements showed that the serum cortisol levels in the participants before the intervention were significantly different from their serum 
cortisol levels before, immediately after, and one month after the intervention $(\mathrm{P}<0.00001)$. However, there was no statistically significant difference in the serum cortisol levels of the participants in the control group in the three stages $(\mathrm{P}>0.05)$. (Table 6)

\begin{tabular}{|c|c|c|c|c|}
\hline Variable & Group & Mean \pm SD & DF & Sig. (t-Test) \\
\hline Age & $\begin{array}{l}\text { Intervention } \\
\text { Control }\end{array}$ & $\begin{array}{l}32.66 \pm 5.60 \\
32.30 \pm 5.36\end{array}$ & 58 & $P=0.797$ \\
\hline $\begin{array}{l}\text { Duration of the } \\
\text { disease }\end{array}$ & $\begin{array}{l}\text { Intervention } \\
\text { Control }\end{array}$ & $\begin{array}{l}7.10 \pm 4.57 \\
5.79 \pm 2.43\end{array}$ & 58 & $P=0.176$ \\
\hline Weight & $\begin{array}{l}\text { Intervention } \\
\text { Control }\end{array}$ & $\begin{array}{l}66.37 \pm 12.98 \\
62.98 \pm 12.40\end{array}$ & 58 & $P=0.257$ \\
\hline Height & $\begin{array}{l}\text { Intervention } \\
\text { Control }\end{array}$ & $\begin{array}{l}162.76 \pm 6.45 \\
161.30 \pm 6.34\end{array}$ & 58 & $P=0.378$ \\
\hline BMI & $\begin{array}{l}\text { Intervention } \\
\text { Control }\end{array}$ & $\begin{array}{l}25.32 \pm 3.95 \\
24.40 \pm 4.19\end{array}$ & 58 & $P=0.382$ \\
\hline EDSS & $\begin{array}{c}\text { Intervention } \\
\text { Control }\end{array}$ & $\begin{array}{l}2.45 \pm 0.338 \\
2.39 \pm 0.446\end{array}$ & 58 & $P=0.448$ \\
\hline
\end{tabular}

\begin{tabular}{|c|c|c|c|c|c|c|c|}
\hline Variable & $\begin{array}{c}\text { Source } \\
\text { of } \\
\text { Change }\end{array}$ & $\begin{array}{l}\text { Sum of } \\
\text { Squares }\end{array}$ & DF & Mean & $\mathbf{F}$ & $\begin{array}{c}\text { Effect } \\
\text { Size }\end{array}$ & Sig. \\
\hline \multirow{4}{*}{ Stress } & Time & 0.3443552 & 1.974 & 0.9131824 & 0.2731 & 0.576 & $<0.00001$ \\
\hline & $\begin{array}{l}\text { Group- } \\
\text { time }\end{array}$ & 0.9001174 & 2 & 587.450 & 0.32810 & 0.484 & $<0.00001$ \\
\hline & Error & 0.0896598 & 116 & 56.880 & & & \\
\hline & Time & 570.033 & 11.767 & 322.515 & 0.45313 & 0.540 & $<0.00001$ \\
\hline \multirow[t]{2}{*}{ Fatigue } & $\begin{array}{l}\text { Group- } \\
\text { time }\end{array}$ & 434.344 & 1.767 & 245.744 & 0.25110 & 0.468 & $<0.00001$ \\
\hline & Error & 0.6222457 & 0.513102 & 23.974 & & & \\
\hline \multirow{3}{*}{$\begin{array}{l}\text { Serum } \\
\text { cortisol } \\
\text { levels }\end{array}$} & Time & 383.685 & 1.377 & 278.638 & 0.42660 & 0.573 & $<0.00001$ \\
\hline & $\begin{array}{l}\text { Group- } \\
\text { time }\end{array}$ & 225.640 & 1.377 & 163.864 & 0.53635 & 0.527 & $<0.00001$ \\
\hline & Error & 368.282 & 0.86679 & 4.611 & & & \\
\hline
\end{tabular}

\begin{tabular}{|c|c|c|c|c|c|}
\hline Variable & Group & Stage (I) & Stage (J) & $\begin{array}{c}\text { Mean } \\
\text { Difference }(I-J)\end{array}$ & Sig. \\
\hline & \multirow{3}{*}{ Intervention } & \multirow{2}{*}{ Pre-test } & Pre-test & 12.333 & $<0.00001$ \\
\hline & & & Follow-up & 16.433 & $<0.00001$ \\
\hline & & Post-test & Follow-up & 4.100 & 0.074 \\
\hline & \multirow{3}{*}{ Control } & \multirow{2}{*}{ Pre-test } & Pre-test & 2.633 & 0.595 \\
\hline & & & Follow-up & 4.733 & 0.070 \\
\hline & & Post-test & Follow-up & 2.100 & 0.728 \\
\hline
\end{tabular}

\begin{tabular}{|c|c|c|c|c|c|}
\hline Variable & Group & Stage (I) & Stage (J) & $\begin{array}{c}\text { Mean } \\
\text { Difference (I-J) }\end{array}$ & Sig. \\
\hline \multirow{6}{*}{ Fatigue } & \multirow{3}{*}{ Intervention } & \multirow{3}{*}{$\begin{array}{l}\text { Pre-test } \\
\text { Post-test }\end{array}$} & Pre-test & 5.363 & $<0.00001$ \\
\hline & & & Follow-up & 8.000 & $<0.00001$ \\
\hline & & & Follow-up & 2.633 & 0.037 \\
\hline & \multirow{3}{*}{ Control } & \multirow{2}{*}{ Pre-test } & Pre-test & 0.667 & 1.000 \\
\hline & & & Follow-up & 0.467 & 1.000 \\
\hline & & Post-test & Follow-up & -0.200 & 1.000 \\
\hline & $\begin{array}{l}\text { 5. Results } \\
\text { Fatique Sco }\end{array}$ & of Bonferr & oni Test to & $\begin{array}{l}\text { Compare the Part } \\
n \text { and Control Gro }\end{array}$ & $\begin{array}{l}\text { ipants' } \\
\text { ps }\end{array}$ \\
\hline
\end{tabular}

\begin{tabular}{|c|c|c|c|c|c|}
\hline Variable & Group & Stage (I) & Stage (J) & $\begin{array}{c}\text { Mean } \\
\text { Difference (I-J) }\end{array}$ & Sig. \\
\hline \multirow{5}{*}{$\begin{array}{l}\text { Serum } \\
\text { cortisol } \\
\text { levels }\end{array}$} & \multirow{2}{*}{ Intervention } & \multirow{2}{*}{$\begin{array}{l}\text { Pre-test } \\
\text { Post-test }\end{array}$} & $\begin{array}{l}\text { Pre-test } \\
\text { Follow-up }\end{array}$ & $\begin{array}{l}4.100 \\
6.213\end{array}$ & $\begin{array}{l}<0.00001 \\
<0.00001\end{array}$ \\
\hline & & & Follow-up & 2.113 & $<0.00001$ \\
\hline & \multirow{3}{*}{ Control } & \multirow{3}{*}{$\begin{array}{l}\text { Pre-test } \\
\text { Post-test }\end{array}$} & Pre-test & 0.597 & 0.755 \\
\hline & & & Follow-up & 0.807 & 0.547 \\
\hline & & & Follow-up & 0.210 & 1.000 \\
\hline
\end{tabular}

\section{DISCUSSION}

The findings of this study showed that there was no significant difference between the two intervention and control groups in terms of demographic characteristics (age, marital status, occupation, type of medicines, the extended disability, duration of the illness, weight, height, and BMI) and both groups were homogeneous. There was no similar study in the literature on the effect of reflexology on fatigue, stress, and cortisol levels of women with multiple sclerosis.

The results of the study indicated that the stress level experienced by the participants in the intervention group was significantly different for the periods before, immediately after, and one month after the intervention $(\mathrm{P}<0.00001)$. However, no statistically significant difference was observed in the stress scores immediately after the intervention, and one month after the intervention $(\mathrm{P}=0.074)$. Besides, there were no significant statistical differences in the stress level experienced by the participants in the control group in the three stages $(\mathrm{P}<0.05)$. The results of a study by Choi and Lee (2015) showed that foot sole reflexology affected stress, depression, and urinary cortisol in the postpartum period..$^{13}$ These conflicting results can be influenced by the different populations studied, and it may not be an effective treatment for all medical conditions as shown in a systematic review by Hernandez-Reif et al. (2009) on the effect of reflexology on various diseases. ${ }^{14}$ The results of a study by Huntley and Ernest showed that massage therapy, as a treatment method, was effective in reducing anxiety, stress, and depression in patients with multiple sclerosis. ${ }^{15}$ Since stress is an important stimulus for the onset and progression of multiple sclerosis, ${ }^{16}$ further research is needed.

The findings of this study on fatigue and cortisol levels showed a significant reduction in fatigue and cortisol levels in the intervention group compared to the control group at different treatment times. In a similar vein, Kabay et al. (2017) showed that fatigue in MS patients is associated with cortisol levels. Similarly, Rigi et al. (2017) and Nazari et al. (2015) showed the effect of reflexology on the fatigue of MS patients. ${ }^{16,17}$ Besides, Najafi et al. ${ }^{18}$ and Oken et al. ${ }^{19}$ showed the effect of yoga training on fatigue, cortisol levels, and adrenocorticotropic hormone in women with multiple sclerosis. Likewise, Wazirinejad et al. showed that the psychological training intervention along with progressive muscle relaxation reduced fatigue in patients with multiple sclerosis. ${ }^{20}$

The results of a study by Mill et al. on the effectiveness of the tai chi technique on the debilitating symptoms of patients with multiple sclerosis also showed that the implementation of tai chi technique calms and relieves the body and reduces fatigue in MS patients. ${ }^{21}$ Besides, Schreurs ${ }^{7}$ showed that physical fatigue was associated with physical disability in MS patients. ${ }^{7}$

Given the importance of the role of stress in inducing MS attacks, worsening symptoms, and increasing fatigue. ${ }^{19}$ and also the significant impact of fatigue on the daily life of MS patients and its adverse effects on patients; physical activities and social functioning, ${ }^{8}$ and also conflicting findings of the effectiveness reflexology, further studies are essential.

\section{CONCLUSIONS}

Foot reflexology has a long-term effect on fatigue and serum cortisol levels and a short-term effect on stress in women with multiple sclerosis. Therefore, this method can be used to 
relieve fatigue, stress, and control cortisol levels in MS patients.

This article was extracted from a master's thesis approved by Rafsanjan University of Medical Sciences with the code of ethics IR.RUMS.REC.1397 and was funded by the university. The authors would like to express their sincere gratitude to all participants who contributed to conducting this study. We also extend our appreciation to all the staff working in the Special Diseases Department of Shahid Sadoughi Hospital in Yazd.

\section{REFERENCES}

[1] Lederman RJ. Bradley's neurology in clinical practice. JAMA 2012;308(16):1694.

[2] Kargarfard M, Eetemadifar M, Mehrabi M, et al. Fatigue, depression, and health-related quality of life in patients with multiple sclerosis in Isfahan, Iran. Eur J Neurol 2012;19(3):431-7.

[3] Kargarfard M, Etemadifar M, Asfarjani F, et al. Changes in quality of life and fatigue in women with multiple sclerosis after 8 weeks of aquatic exercise training. Journal of Fundamentals of Mental Health 2010;12(3):562-73.

[4] Motl RW, McAuley E, Snook EM. Physical activity and multiple sclerosis: a meta-analysis. Mult Scler 2005;11(4):459-63.

[5] Etemadifar M, Sajjadi S, Nasr Z, et al. Epidemiology of multiple sclerosis in Iran: a systematic review. Eur Neurol 2013;70(5-6):356-63.

[6] Dehghan A, Memarian R. Abundance of stress, anxiety, and depression in MS patients. Alborz University Medical Journal 2018:82(2):82-8.

[7] Schreurs KMG, de Ridder DTD, Bensing JM. Fatigue in multiple sclerosis: reciprocal relationships with physical disabilities and depression. J Psychosom Res 2002;53(3):775-81.

[8] Besharat MA, Barati N, Lotfi J. Relationship between coping styles and mental health in a sample of MS patients. Research in Medicine 2008;32(1):27-35.

[9] Shahreza MS, Nazari F, Shayegannejad V, et al. The effects of reflexology on physical symptoms in women with multiple sclerosis. Complementary Medicine Journal Arak University of Medical Scicnces 2014;4(2):820-30.
[10] Krupp LB, LaRocca NG, Muir-Nash J, et al. The fatigue severity scale. Application to patients with multiple sclerosis and systemic lupus erythematosus. Arch Neurol 1989;46(10):1121-3.

[11] Pazokian M, Shaban M, Zakerimoghdam M, et al. The effect of stretching together aerobic exercises on fatigue level in multiple sclerosis patients refer to MS society of Iran those suffer from fatigue. Journal of Holistic Nursing And Midwifery 2012;22(2):18-24.

[12] Khodayarifard M, Parand A. Stress and ways to deal with it Author; Powell TJ, Vanerit Sen J. Mashhad (Iran): Beh Publication 2001.

[13] Choi MS, Lee EJ. Effects of foot-reflexology massage on fatigue, stress, and postpartum depression in postpartum women. J Korean Acad Nurs 2015;45(4):587-94.

[14] Hernandez-Reif M, Field T, Theakston H. Multiple sclerosis patients benefit from massage therapy. Journal of Bodywork and Movement Therapies 1998;2(3):16874.

[15] Huntley A, Ernst E. Complementary and alternative therapies for treating multiple sclerosis symptoms: a systematic review. Complement Ther Med 2000;8(2):97105.

[16] Nazari F, Shahreza MS, Shaygannejad V, et al. Comparing the effects of reflexology and relaxation on fatigue in women with multiple sclerosis. Iran J Nurs Midwifery Res 2015;20(2):200-4.

[17] Rigi F, Masoomeh S, Adineh HA, et al. The effect of reflexology massage on the fatigue severity in women with multiple sclerosis. Journal of Urmia Nursing And Midwifery Faculty 2017;14(11):926-33.

[18] Najafi P, Moghadasi M. The effect of yoga training on the enhancement of adrenocorticotropic hormone (ACTH) and cortisol levels in female patients with multiple sclerosis. Complement Ther Clin Pract 2017;26:21-5.

[19] Oken BS, Kishiyama S, Zajdel D, et al. Randomized controlled trial of yoga and exercise in multiple sclerosis. Neurology 2004;62(11):2058-64.

[20] Vazirinejad R, Jafarzadeh A, Yassini SM, et al. Effectiveness of psychological training with gradual muscle relaxation technique on fatigue in multiple sclerosis patients. Acta Medica Mediterranea 2016;32(4):987-90.

[21] Mills N, Allen J, Carey-Morgan S. Does Tai Chi/Qi Gong help patients with Multiple sclerosis. Journal of BodyWork and Movement Therapies. 2000;4(1):39-48. 